\title{
PENGARUH PEMBERIAN COKELAT HITAM (DARK CHOCOLATE) DAN JAHE TERHADAP INTENSITAS NYERI HAID (DYSMENORRHEA)
}

\author{
${ }^{1}$ Nurul Faizah, ${ }^{2}$ Mukhoirotin \\ Fakultas Ilmu Kesehatan, Unipdu Jombang \\ Email: nurulfaizah497@gmail.com
}

\begin{abstract}
ABSTRAK
Dismenore merupakan nyeri pada waktu haid berupa kram pada perut bawah dan panggul, apabila masalah ini tidak diatasi akan berdampak pada kegiatan sehari-hari. Intervensi nonfarmakologi yang digunakan untuk menangani nyeri haid yaitu menggunakan cokelat hitam dan jahe. Tujuan penelitian ini adalah untuk menjelaskan pengaruh pemberian cokelat hitam dan jahe terhadap intensitas nyeri haid. Desain penelitian menggunakan Quasy Experiment dengan pendekatan Pretest-Postest Design, pengambilan sampel dengan teknik Purposive Sampling. Jumlah populasi penelitian adalah 53 responden. Subyek penelitian sebanyak 36 responden (kelompok coklat hitam n=18, Kelompok jahe $\mathrm{n}=18$ ). Pemberian cokelat hitam sebanyak 100 gram dan jahe $1500 \mathrm{mg}$ diberikan pada hari pertama menstruasi. Intensitas nyeri dikaji dengan Numeric Rating Scale (NRS). Uji statistik menggunakan Paired $t$ test dan Independent $t$ test. Hasil penelitian didapatkan ntensitas nyeri haid sebelum diberikan intervensi pada kelompok cokelat hitam dan jahe adalah sebanding ( $>>0.05)$. Intensitas nyeri haid pada kelompok cokelat hitam menurun secara signifikan dari 5.44 menjadi 2.56 dan intensitas nyeri pada kelompok jahe menurun secara signifikan dari 5.28 menjadi 1,89. Tidak ada perbedaan pengaruh antara pemberian cokelat hitam dan jahe terhadap dysmenorrhea $(2.56 \pm 1.75$ vs $1.89 \pm 1.45 ; \mathrm{p}>0.05)$. Dark Chocolate mengandung triptophan yang dapat merangsang pengeluaran serotonin sementara jahe mengandung komponen bioaktif yang terdiri dari gingerol dan shogaol yang berfungsi untuk antiinflamasi yang memblokir prostaglandin sehingga intensitas nyeri haid menurun.
\end{abstract}

Kata kunci: nyeri haid, cokelat hitam (dark chocolat), jahe

\begin{abstract}
Dysmenorrhea is menstrual pain in the form of cramps in the lower abdomen and pelvis, if this problem is not resolved it will interfere with daily activities. Non-pharmacological interventions that can be used to treat menstrual pain are using Dark Chocolate and Ginger. The purpose of this research is to determine the effect of giving the Dark chocolate and Ginger to the Menstrual pain intensity. Research design used was the Quasy Experiment with approach Pretest-Postest Design, the sampling in this research using a Purposive Sampling technique. The number of samples was 36 respondents (dark chocolate group $\mathrm{n}=18$, ginger group $\mathrm{n}=18$ ). The giving 100 grams of Dark chocolate and 1500 milligrams of Ginger on the first day of Menstruation. The Menstrual pain intensity measured by Numeric Rating Scale (NRS). The statistic test used the Paired t test and Independent $t$ test. The results of the research showed the Menstrual pain intensity before being given intervention in both groups was comparable. The menstrual pain intensity in the dark chocolate group decreased significantly from 5.44 to 2.56 and the menstrual pain intensity in the ginger group decreased significantly from 5.28 to 1.89 . There is no difference in influences between the giving of Dark chocolate and Ginger against Dysmenorrhea (2.56 \pm 1.75 vs $1.89 \pm 1.45: \mathrm{P}>0.05)$. The dark chocolate contain with triptophan wich can stimulate expenditure of serotonin and the ginger contain with oleororesin wich is a bioactive component consisting of gingerol and shogaol it functions as an inflammatory which can block the prostaglandin so that it can be decrease the menstrual pain intensity.
\end{abstract}

Key words: dysmenorrhea, dark chocolate, ginger 


\section{PENDAHULUAN}

Menstruasi merupakan keluarnya darah dan sel sel tubuh dari vagina yang berasal dari dinding uterus wanita secara periodik (Dito, 2011 Cit Erlina, 2014). Akan tetapi, haid yang dialami para wanita remaja dapat menimbulkan masalah, salah satunya adalah dysmenorrhea atau nyeri haid. Nyeri haid (dismenorrhea) merupakan keluhan nyeri selama haid dan nyeri biasanya dirasakan menekan kebawah, pegal atau kram pada perut bawah serta pangul. Nyeri haid (dismenorrhea) seringkali dimulai setelah mengalami menstruasi pertama. Nyeri berkurang setelah haid, tetapi nyeri bisa terus dialami selama periode menstruasi pada beberapa wanita sehingga berdampak pada kegiatan sehari-hari (Mukhoirotin \& Fatmawati, 2016).

Sebanyak 30-60\% remaja wanita yang mengalami dismenore, sebanyak $7-15 \%$ didapatkan dysmenorrhea yang mengganggu kegiatan sekolah dan pekerjaan (Ningsih, 2012 Cit Larasati dan Faridah, 2016). Beberapa alternatif yang dilakukan untuk mengatasi dysmenorrhea adalah dengan akupunktur, akupresur, manipulasi tulang belakang, dan terapi herbal (Jenabi, 2013). Terapi herbal yang dapat menurunkan intensitas nyeri haid adalah dengan pemberian jahe dan cokelat hitam.

Masalah yang dialami wanita saat haid sebanyak $90 \%$ dari remaja di dunia dan $>50 \%$ mengalami dysmenorrhea primer dengan 10$20 \%$ dari mereka mengalami gejala yang cukup parah (Berkley, 2015). Di Indonesia kejadian dysmenorrhea diperkirakan sekitar $55 \%$ wanita usia produktif mengalami dismenore. Prevalensi dysmenorrhea pada perempuan produktif adalah 45-95 \% (Prajati, 2015 Cit Kusmiyati, 2016).

Data awal yang diperoleh di Asrama As'adiyah Pondok Pesantren Tinggi Darul 'Ulum Jombang tanggal 15 November 2018 didapatkan dari 77 remaja putri sebagian besar mengalami nyeri saat menstruasi sebanyak 53

\section{METODE PENELITIAN}

Penelitian ini menggunakan desain Quasy Experiment dengan pendekatan Pretest-Postest Design, pengambilan sampel dengan teknik Purposive Sampling. Jumlah sampel sebanyak 36 responden, masingmasing responden berjumlah 18 responden
(68\%) responden, dengan intensitas nyeri ringan sebanyak $11(14 \%)$ responden, nyeri sedang sebanyak $31(40 \%)$ responden dan nyeri berat sebanyak 11 (14\%) responden. Keluhan nyeri terasa pada bagian pinggang dan panggul, mamae terasa kencang, pusing, perut terasa sebah, mual, rasa seperti ingin $\mathrm{BAB}$ dan berat, sehingga kegiatan sehari hari terganggu dan tidak masuk sekolah. Tindakan yang dilakukan saat nyeri haid yaitu beristirahat serta minum obat pereda nyeri.

Dysmenorrhea primer terjadi karena prostaglandin $(P G)$ F2-alfa berlebih yang merupakan suatu siklooksigenase (COX-2) berdampak pada hipertonus dan vasokonstriksi myometrium, iskemia dan nyeri pada perut bagian bawah (Marlina, 2012 Cit Larasati dan Faridah, 2016). Dysmenorrhe sekunder adalah nyeri haid berulang yang dihasilkan dari penyebab abnormalitas yang dapat diidentifikasi secara klinis. Penyebab umum dysmenorrhe sekunder (seperti fibroid, adhesi pelvis, adenomiosis), terjadi pada wanita dengan usia lebih tua (Smith dan Turec, 2011). Gejala dismenore pada remaja diantaranya kekakuan atau kejang pada perut bagian bawah. Rasanya sangat tidak nyaman berdampak mudah marah, tersinggung, mual, muntah, berat badan meningkat, perut kembung, nyeri punggung, sakit kepala, timbul jerawat, tegang, lesu, dan depresi (Parker et al., 2010 Cit Larasati dan Faridah, 2016). Jika keluhan nyeri tidak segera ditangani, pada gangguan aktivitas sehari-hari (ADLs) (USMLE, 2018).

Penanganan dysmenorrhea dapat dilakukan dengan tindakan farmakologi dan nonfarmakologi. Secara farmakologis dengan pemberian analgesik oral, terapi hormonal, dan terapi dengan obat OAINS (Obat antiinflamasi nonsteroid). Namun, hal tersebut dapat menyebabkan efek buruk pada beberapa sistem tubuh, sehingga pada akhirnya akan membutuhkan alternatif terapi untuk jangka panjang (Wulandari dan Afriliana, 2017). Terapi alternatif untuk menurunkan nyeri adalah mengonsumsi cokelat hitam dan jahe.

pada kedua kelompok. Pemberian cokelat hitam (dark chocolate) sebanyak 100 gram dan jahe 1500 mili gram yang diberikan pada hari pertama menstruasi. Intensitas nyeri diobservasi dengan Numeric Rating Scale (NRS). Data diuji dengan Paired t test dan Independent $t$ test. 
HASIL PENELITIAN

Table 1.1 Karakteristik Responden dan Homogenitas

\begin{tabular}{|c|c|c|c|c|c|}
\hline \multirow{2}{*}{ Variabel } & \multicolumn{2}{|c|}{ Dark Chocolate } & \multicolumn{2}{|c|}{ Jahe } & \multirow{2}{*}{$\mathrm{p}$ value } \\
\hline & $\mathrm{N}$ & $\%$ & $\mathrm{~N}$ & $\%$ & \\
\hline \multicolumn{6}{|l|}{ Usia } \\
\hline a. Remaja awal (12-14 tahun) & 4 & 22.2 & 6 & 33.3 & \multirow{3}{*}{0.778} \\
\hline b. Remaja tengah (15-17 tahun) & 9 & 50 & 8 & 44.4 & \\
\hline c. Remaja akhir (18-21 tahun) & 5 & 27.8 & 4 & 27.7 & \\
\hline \multicolumn{6}{|l|}{ Pendidikan } \\
\hline a. SMP & 11 & 61.1 & 9 & 50 & \multirow{3}{*}{0.198} \\
\hline b. SMA & 5 & 27.8 & 7 & 38.9 & \\
\hline c. Mahasiswa & 2 & 11.1 & 2 & 11.1 & \\
\hline \multicolumn{6}{|l|}{ Usia menarche } \\
\hline a. Menarche normal (11-13 tahun) & 14 & 77.8 & 14 & 77.8 & \multirow[t]{2}{*}{0.405} \\
\hline b. Menarche lambat (>13 tahun) & 4 & 27.7 & 4 & 27.7 & \\
\hline \multicolumn{6}{|l|}{ Lama menstruasi } \\
\hline a. Periode normal (1-7 hari) & 13 & 72.2 & 15 & 83.3 & \multirow[t]{2}{*}{0.119} \\
\hline b. Periode panjang (8- 15 hari) & 5 & 27.8 & 8 & 16.7 & \\
\hline \multicolumn{6}{|l|}{ Jumlah menstruasi } \\
\hline a. Sedikit & 6 & 33,3 & 5 & 27.8 & \multirow{3}{*}{0.498} \\
\hline b. Sedang & 9 & 50 & 11 & 61.1 & \\
\hline c. Banyak & 3 & 16.7 & 2 & 11.1 & \\
\hline \multicolumn{6}{|l|}{ Cara mengatasi nyeri } \\
\hline a. Istirahat & 9 & 50 & 6 & 33.3 & \multirow[t]{2}{*}{0.157} \\
\hline b. Dibiarkan & 9 & 50 & 12 & 66.7 & \\
\hline
\end{tabular}

Sumber: Data Primer, 2019

Berdasarkan uji homogenitas pada variable usia, usia menarche, pendidikan, lama menstruasi, jumlah menstruasi dan cara mengatasi nyeri adalah homogen dengan $\mathrm{p}$

value $>0.05$, berarti bahwa semua responden pada kelompok cokelat hitam dan kelompok jahe memiliki karakteristik subyek yang homogen.

Tabel 1.2 Intensitas Nyeri Haid Sebelum Pemberian Kelompok Cokelat Hitam (Dark Chocolate) dan Jahe.

\begin{tabular}{ccccc}
\hline \multirow{2}{*}{ Intensitas Nyeri Haid } & \multicolumn{2}{c}{ Cokelat Hitam } & \multicolumn{3}{c}{ Jahe } \\
\cline { 2 - 5 } & $\mathrm{N}$ & $\%$ & $\mathrm{~N}$ & $\%$ \\
\hline Ringan & 2 & 11,1 & 3 & 16,7 \\
Sedang & 12 & 66,7 & 11 & 61,1 \\
Berat & 4 & 22,2 & 4 & 22,2 \\
\hline Jumlah & 18 & 100 & 18 & 100 \\
\hline
\end{tabular}

Sumber: Data Primer, 2019

Berdasarkan tabel 1.2 di atas, rata-rata intensitas nyeri haid sebelum diberikan cokelat hitam (dark chocolate) sebagian kecil mengalami nyeri ringan sebanyak $2(11.1 \%)$ responden, sebagian besar nyeri sedang 12 $(66.7 \%)$ responden serta sebagian kecil mengalami nyeri berat sebanyak $4(22.2 \%)$ responden. Sedangkan pada jahe sebagian kecil nyeri ringan $3(16.7 \%)$ responden, sebagian besar nyeri sedang $11(61.1 \%)$ responden dan nyeri berat sebanyak $4(22.2$ $\%)$ responden.

Tabel 1. 3 Pengaruh Cokelat Hitam (Dark Chocolate) dan Jahe terhadap Intensitas Nyeri Haid (Dismenorea)

\begin{tabular}{lllc}
\hline & Kelompok & Mean (SD) & $\mathrm{p}$ \\
\hline Cokelat Hitam & Pretest & $5.44(1.46)$ & 0.000 \\
& Post Segera & $5.33(1.53)$ & \\
& Post 30 Menit & $5.00(1.91)$ & \\
\hline
\end{tabular}




\begin{tabular}{llll}
\hline & Post 1 Jam & $4.44(1.95)$ & \\
& Post 2 Jam & $3.61(1.79)$ & \\
Post 3 Jam & $2.56(1.76)$ & 0.000 \\
\hline Jahe & Pretest & $5.28(1.57)$ & \\
Post Segera & $5.22(1.56)$ & \\
Post 30 Menit & $4.67(2.00)$ & \\
Post 1 Jam & $4.06(1.89)$ & \\
Post 2 Jam & $3.17(1.72)$ & \\
& Post 3 Jam & $1.89(1.45)$ & \\
\hline
\end{tabular}

Uji Repeated Anova.

Tabel 1.3 Analisis post hoc

\begin{tabular}{llcccc}
\hline & Kelompok & Beda & \multicolumn{2}{c}{ CI 95\% } & $\mathrm{p}$ \\
\cline { 4 - 5 } & & Mean & Minimum & Maksimum nnn & \\
\hline Cokelat Hitam & Pretest vs Post Segera & 0.11 & -0.15 & 0.36 & 1.000 \\
& Pretest vs Post 30 Menit & 0.44 & -0.12 & 1.01 & 0.240 \\
& Pretest vs Post 1 Jam & 1.00 & 0.17 & 1.83 & 0.011 \\
& Pretest vs Post 2 Jam & 1.83 & 0.99 & 2.67 & 0.000 \\
& Pretest vs Post 3 Jam & 2.89 & 2.17 & 3.61 & 0.000 \\
\hline Jahe & Pretest vs Post Segera & 0.06 & -0.13 & 0.25 & 1.000 \\
& Pretest vs Post 30 Menit & 0.61 & -0.01 & 1.24 & 0.058 \\
& Pretest vs Post 1 Jam & 1.22 & 0.46 & 1.98 & 0.001 \\
& Pretest vs Post 2 Jam & 2.11 & 1.50 & 2.72 & 0.000 \\
& Pretest vs Post 3 Jam & 3.39 & 2.76 & 4.01 & 0.000 \\
\hline
\end{tabular}

Uji Pairwise Comparison (Bonferroni)

Hasil analisis Repeated Anova menunjukkan ada pengaruh cokelat hitam dan jahe terhadap intensitas nyeri haid $(\mathrm{p}<0.05)$. Hasil uji Post Hoc Pairwise Comparison (Bonferroni) menunjukkan bahwa pada pengukuran post segera dan post 30 menit tidak langsung mengalami penurunan nyeri. Hal ini dikarenakan pemberian cokelat hitam dan jahe merupakan terapi yang diberikan melalui oral (dimakan dan diminum) sehingga melalui proses penyerapan dipencernaan terlebih dahulu. Setelah 1 jam pemberian menunjukkan ada pengaruh pemberian cokelat hitam (dark chocolate) dan jahe terhadap penurunan intensitas nyeri haid (Dysmenorrhea) dengan $p$ value $<0.05$.

Tabel 1.4. Perbedaan pengaruh pemberian cokelat hitam (dark chocolate) dan jahe sesudah dilakukan intervensi pada bulan April - Mei 2019.

\begin{tabular}{lcccc}
\hline & $\begin{array}{c}\text { Cokelat Hitam } \\
\text { Mean (SD) }\end{array}$ & $\begin{array}{c}\text { Jahe } \\
\text { Mean (SD) }\end{array}$ & $\begin{array}{c}\text { Beda Mean } \\
(\mathbf{9 5 \%} \text { CL) }\end{array}$ & P \\
\hline Post segera & $5.33 \pm 1.53$ & $5.28 \pm 1.56$ & $0.11(-0.961-1.183)$ & 0.834 \\
\hline Post 30 menit & $5.00 \pm 1.91$ & $4.67 \pm 2.00$ & $0.33(-0.991-1.658)$ & 0.612 \\
\hline Post 1 Jam & $4.44 \pm 1.94$ & $4.11 \pm 1.93$ & $0.33(-0.982-1.649)$ & 0.610 \\
\hline Post 2 Jam & $3.61 \pm 1.78$ & $3.17 \pm 1.72$ & $0.44(-0.745-1.634)$ & 0.453 \\
\hline Post 3 Jam & $2.56 \pm 1.75$ & $1.89 \pm 1.451$ & $0.67(-0.425-1.758)$ & 0.223 \\
\hline
\end{tabular}

Berdasarkan tabel diatas menunjukkan bahwa pada post segera post 30 menit, post 1 jam, post 2 jam, dan post 3 jam tidak ada perbedaan penurunan intensitas PEMBAHASAN

Hasil penelitian menunjukkan bahwa pada intervensi pemberian cokelat hitam (dark chocolate) dan jahe sebagian besar mengalami nyeri haid antara kelompok pemberian pemberian cokelat hitam (dark chocolate) dan jahe dengan $\mathrm{p}$ value $>0,05$.

nyeri sedang sebanyak $12(66,7 \%)$ responden dan $11(61,1 \%)$ reponden, nyeri ringan sebanyak $2(11,1 \%)$ responden dan $3(16,7 \%)$ 
responden, mengalami nyeri berat masingmasing sebanyak $4(22,2 \%)$ responden.

Nyeri haid (Dismenorrhea) adalah nyeri selama atau sesaat sebelum menstruasi. Dismenore dapat memberikan dampak bagi sebagian wanita, salah satu dampaknya adalah menyulitkan aktivitas sehari-hari mereka (Mukhoirotin et al, 2018). Nyeri haid (dismenorrhea) disebabkan oleh produksi dan pelepasan prostaglandin yang berlebihan, menyebabkan kontraksi otot polos, mual atau diare. Gejalanya adalah nyeri teratur setiap bulan seperti nyeri perut, pelvis, mual, diare atu konstipasi, lemah, pusing, kenaikan berat badan, tendensi payudara dan sakit punggung parah (Pangastuti \& Mukhoirotin, 2018).

Beberapa faktor yang berpengaruh adalah usia menarche, lama menstruasi, jumlah menstruasi dan siklus menstruasi. Usia responden pada kedua kelompok pada penelitian ini didapatkan pada remaja berusia 12 sampai 21 tahun dengan kategori usia remaja awal (12-14 tahun), remaja tengah (15117 tahun) dan remaja akhir (18-21 tahun). Hasil penelitian ini sesuai dengan pendapat Sohyune (2016) yang menyatakan bahwa dysmenorrhea terjadi terutama pada usia 10 sampai 20 tahun dan dapat bertahan sampai $40 \%$ wanita, tetapi dysmenorrhea dapat terjadi pada semua tingkat usia. Hasil penelitian didapatkan usia menarche pada kedua kelompok dikategorikan menjadi menarche normal (11-13 tahun), menarche lambat (14-16 tahun) dan menarche dini $(<11$ tahun), Masa pra-pubertas remaja dimulai umur 12 tahun (Nirwana, 2011). Siklus menstruasi dini biasanya tidak beraturan. Menarche dini berdampak pada alat - alat reproduksi belum berfungsi optimal dan belum siap mengalami perubahan - perubahan sehingga timbul nyeri saat menstruasi (Kail dan Cavanaugh, 2017). Siklus menstruasi responden pada kedua adalah teratur sesuai dengan syarat inklusi.

Hasil dari responden yang mengalami dysmenorrhea pada kedua kelompok berdasarkan lama menstruasi dan jumlah menstruasi didapatkan bahwa periode menstruasi panjang sebanyak 5 responden dan 3 responden. Sedangkan jumlah menstruasi pada kedua kelompok responden separuhnya berjumlah sedang. Hal ini sesuai dengan teori yang panjang akanmengalami dysmenorrhea (Arulkumuran, 2006 cit priyanti, 2014). Ketika durasi kontraksi uterus lama, sangat berhubungan dengan frekuensi prostaglandin yang dilepaskan bersamaan dengan menstruasi sehingga menyebabkan nyeri (Gold dan Josimovich, 2013).

Hasil penelitian didapatkan bahwa intensitas nyeri haid pada kedua kelompok berada di skor 4,5,6 dimana intensitas nyeri tersebut dikategorikan sebagai nyeri sedang. Responden dalam penelitian ini adalah SMP, SMA, dan Mahasiswa, selain kegiatan di asrama responden sibuk dengan kegiatan di luar asrama. Keadaan ini menstimulasi stress dan keletihan yang akan meningkatkan presepsi nyeri (Potter \& Perry, 2010).

Sesudah pemberian intervensi Cokelat hitam (dark chocolate) setelah 3 jam sebagian besar responden mengalami nyeri ringan sebanyak $11(61,1 \%)$ responden, hampir separuhnya mengalami nyeri ringan sebanyak $6(33,3 \%)$ respondendan sebagian kecil mengalami tidak nyeri sebanyak 2 $(11,1 \%)$ responden. Setelah 3 jam pemberian jahe sebagian besar mengalami nyeri ringan sebanyak $13(72,2 \%)$ responden, sebagian kecil tidak nyeri sebanyak 3 (16,7\%) responden, dan $2(11,1 \%)$ responden mengalami nyeri sedang. Setelah 3 jam pemberian cokelat hitam (Dark Chocolate) dan jahe menunjukkan ada penurunan intensitas nyeri haid (Dysmenorrhea).

Cokelat merupakan salah satu produk makanan olahan yang terdiri dari campuran pasta cokelat (chocolate liquor), lemak kakao, gula, dan beberapa macam bahan tambahan perasa. Kandungan polifenol memberikan rasa sepat dan pahit pada biji kakao. Kandungan kakao cokelat hitam lebih banyak bila dibandingkan dengan beberapa jenis cokelat yang lain, sehingga kandungan senyawa polifenol cokelat hitam lebih banyak yang berkontribusi dalam rasa pahit serta warna hitam pekat. Cokelat hitam merupakan pilihan utama bagi segi kesehatan. Manfaat coklat bagi tubuh, diantaranya melepas neurotransmitter sehingga meningkatkan suasana hati dan kaya antioksidan. Selain itu, cokelat mengandung mineral dan vitamin, serta menstimulasi otak untuk melepaskan hormon endorphin (Arfailasufandi, 2018). Jahe menjadi pilihan karena tingginya kandungan oleororesin. Oleororesin merupakan komponen bioaktif yang terdiri dari gingerol dan shogaol yang berfungsi sebagai antiinflamasi yang dapat memblokir prostaglandin sehingga dapat menurunkan 
intensitas dismenorhea (Ozgoli et al., 2009 dalam Rahayu dan Nujula, 2016).

Analisa sesudah pemberian intervensi cokelat hitam (dark chocolate) dan jahe pada kedua kelompok mempunyai pengaruh terhadap intensitas nyeri haid pada responden yang mengalami dysmenorrhea, dilihat dari tingkat keparahan nyeri yang dialami, responden sudah merasakan berkurang nyerinya. Hasil penelitian ini menunjukkan bahwa cokelat hitam (dark chocolate) dan jahe efektif menurunkan intensitas nyeri haid dan tidak terdapat perbedaan pada kelompok cokelat hitam dan kelompok jahe. Penelitian sebelumnya yang dilakukan oleh Utami, et al., (2017) pada cokelat hitam (dark chocolate) dan Rahmana, et al (2012) pada jahe, juga menunjukkan bahwa intervensi tersebut efektif menurunkan nyeri haid.

Hasil analisis Repeated Anova menunjukkan bahwa pada pengukuran post segera tidak langsung mengalami penurunan nyeri, sedangkan pada post 30 menit mengalami penurunan tapi tidak signifikan. Hal ini dikarenakan pemberian cokelat hitam dan jahe merupakan terapi yang diberikan melalui oral (dimakan dan diminum) sehingga melalui proses penyerapan dipencernaan terlebih dahulu. Namun, pada post 1 jam, post 2 jam, post 3 jam ada pengaruh pemberian cokelat hitam (dark chocolate) dan jahe terhadap penurunan intensitas nyeri haid (Dysmenorrhea) dengan $p$ value $<0,05$.

Hasil uji independent t-test didapatkan tidak ada perbedaan intensitas nyeri haid yang bermakna antara kelompok cokelat hitam dan kelompok jahe pada post segera, post 1 jam, post 2 jam dan post 3 jam (p>0.05). Hasil uji tersebut menunjukkan tidak ada perbedaan pengaruh intervensi pemberian cokelat hitam (dark chocolate) dan jahe terhadap penurunan intensitas nyeri haid.

Secara statistik menunjukkan bahwa pemberian cokelat hitam dan jahe sama-sama efektif menurunkan intensitas nyeri haid, akan tetapi dilihat dari perbedaan rata-rata intensitas nyeri haid pemberian jahe lebih efektif dibandingkan dengan cokelat hitam. Karena kandungan shogaol pada jahe menghasilkan rasa hangat sehingga menimbulkan efek relaksasi. Keadaan relaksasi mampu menstimulasi tubuh untuk membentuk system penekanan nyeri sehingga terjadi penurunan nyeri (Huges., et al, 2005 Cit Nurrianingsih, 2015).

\section{KESIMPULAN DAN SARAN}

Hasil penelitian menunjukkan bahwa pemberian cokelat hitam dan jahe efektif menurunkan intensitas nyeri haid. Tidak ada perbedaan pengaruh antara pemberian cokelat hitam dan jahe terhadap dysmenorrhea. Untuk penelitian selanjutnya sebaiknya observasi pengukuran setelah pemberian cokelat hitam dan jahe lebih dari 3 jam untuk mengetahui sejauh mana pemberian cokelat hitam dan jahe bisa menurunkan intensitas nyeri haid (Dysmenorrhea) dan dapat mengkombinasikan antara cokelat hitam dan jahe.

\section{DAFTAR PUSTAKA}

Arfailasufandi, Roiela \& Andiarna, Funsu. (2018). The Influence of Dark Chocolate to Reduce Menstrual Pain in Primary Dysmenorhea. Journal of Health Science and Prevention, Vol.2(1), April:27-35

Berkley KJ. (2013). Primary dysmenorrhea: an urgent mandate. International Association for the Study of Pain. Diakses tanggal 25 November 2018. Pukul 07.05.

Erlina, Rustam. (2014). Gambaran Pengetahuan Remaja Putri Terhadap Nyeri Haid Dan Cara Penanggulangannya. Jurnal Andalas; 3(1): 286-290

Mukhoirotin \& Fatmawati DA (2016). Pengaruh Akupresur Pada Titik Sanyinjiao dan Slow Stroke Back Massage Terhadap Penurunan Intensitas NyeriHaid (Dismenorrhea)

Gold, J, J., \& Josimovich, J. B. (2013). Gynecologic Endocrinology Fourth Edition. New York: Plenum Publishing Corparation.

Jenabi, Ensiyeh. 2013. The Effect of Ginger for Relieving of Primary Dysmenorrhoea. J Pak Med Assoc: 810

Kail, R. V., \& Cavanaugh, J. (2017). Essentials of Human Development Second Edition. USA: Cengage Learning.

Kusmiyati, et al. (2016). Studi Pengetahuan Tentang Menstruasi Dengan Upaya Penanganan Dismenore Pada Mahasiswa Pendidikan Biologi. J. Pijar MIPA, Vol. XI No.1, Maret: 47-50 
Larasati, TA., dan Faridah, Alatas. 2016. Dismenore Primer dan Faktor Risiko Dismenore Primer pada Remaja. Majority Volume 5 Nomor 3 September: 79-84

Mukhoirotin, Fatmawati D A and Sabrina Dwi Prihartini (2018). Potential of Acupressure on Sanyinjiao Point, Hegu Point and Massage Efflurage to Decrease Menstrual Pain Intensity. $J$. Appl. Environ. Biol. Sci., 8(3)51-59, 2018

Nirwana, A.B. (2011). Psikologi Kesehatan Wanita. Yogyakarta: Nuha Medika

Nurrianingsih, Peni. (2015). Pengaruh Teknik Relaksasi Terhadap Tingkat Dismenorea Pada Siswi SMA Muhammadiyah 3 Yogyakarta. Diakses tanggal 19 Juli 2019. Pukul 07.40

Pangastuti D \& Mukhoirotin. (2018). Pengaruh Akupresur Pada Titik Tai Chong Dan Guanyuan Terhadap Penurunan Intensitas Nyeri Haid (Dismenorhea) Pada Remaja Putri. Jurnal EDUNursing, Vol2, No2, September 2018

Priyanti, S., \& Mustikari, A. D. (2014). Hubungan Tingkat Stress Terhadap Dismenore Pada Remaja Putrid Madrasah Aliyah Mamba 'Ul Ulum Mojosari Mojokerto. Diakses tanggal 05 Januari 2019. Pukul 05.40.

Potter \& Perry. (2010). Fundamental Keperawatan, Volume 1 \& 2, ed. 7. Jakarta: Salemba Medika.

Rahayu, Kurnia Dan Nujulah, Lailatul. (2015). Pengaruh Pemberian Jahe Terhadap Intensitas Nyeri Haid Pada Mahasiswi Kebidanan Sakinah Pasuruan. Akademi Kebidanan Sakinah Pasuruan: 69-72

Rahnama, Parvin et al. (2012). Effect of Zingiber Officinale R. Rhizomes (Ginger) On Pain Relief in Primary Dysmenorrhea: A Placebo Randomized Trial. BMC Complementary and Alternative Medicine, 12:92: 1-8

USMLE. (2018). STEP 2 CK Lecture Notes 2018 Obstetrics and Gynecology. New York: Kaplan.

Utami, Pinilih Pangesti, et al. (2017). Wulandari, Siswi \& Afriliana, Fitra Dwi. (2017). The Effect of Consumption Dark Chocolate Against
Primary Dismenore Pain for Girls Teenager at Kediri 5 High School. Indian Journal of Medical Research and Pharmaceutical Sciences. 4(2): 1723. 